\title{
Vibrational Relaxation in Several Derivatives of Benzene
}

\author{
Bogumił B. J. Linde • Ewa B. Skrodzka • \\ Nikołaj B. Lezhnev
}

Received: 19 April 2011 / Accepted: 27 January 2012 / Published online: 23 February 2012

C The Author(s) 2012. This article is published with open access at Springerlink.com

\begin{abstract}
Acoustical spectroscopy at frequencies up to $10 \mathrm{GHz}$ gives the possibility of the investigation of liquid substances, where the relaxation process observed is caused by energy transfer between translational and vibrational degrees of freedom. The compounds presented in this article belong to this group of liquids. The acoustic investigations in the group of benzene derivatives, particularly research of the dependencies of acoustic parameters and the structure of organic liquids, demonstrated some interesting regularities in the group of these compounds in gas and liquid states. In this article, the results of research on five cyclic liquids: bromo-, chloro-, fluoro-, iodo-, and nitrobenzene as well as toluene and aniline are discussed and compared to benzene. The acoustic relaxation observed in all these compounds was found to result from Kneser's processes (vibrational relaxation). Based on investigations reported in this article, as well as by other authors, and taking into account experimental and literature data concerning a great number of compounds, one can draw a conclusion that almost all acoustic relaxation (Kneser-type) processes in liquids can be described using a single relaxation time. It also seems that all vibrational degrees of freedom of the molecule take part in this process. It is known that the appearance of differences in transition probabilities could be caused by additional attraction in interactions of molecules having dipole moments. Halogen derivatives have higher values of dipole moments than benzene. This difference could be responsible for the
\end{abstract}

\author{
B. B. J. Linde $(\bowtie)$ \\ Institute of Experimental Physics, University of Gdańsk, ul Wita Stwosza 57, 80-952 Gdańsk, Poland \\ e-mail: fizbl@univ.gda.pl \\ E. B. Skrodzka \\ Institute of Acoustics, A. Mickiewicz University, Umultowska 85, 61-614 Poznań, Poland \\ N. B. Lezhnev \\ Oil \& Gas Institute of State Concern “TURKMENGAS," Ashgabat, Turkmenistan
}


difference of transition probabilities and changes in the relaxation times. However, benzene derivatives with amino, nitro, and methyl groups and halides show the other type of relaxation.

Keywords Absorption of ultrasound - Molecular acoustics · Organic liquids · Ultrasonic relaxation · Velocity of ultrasound

\section{Introduction and Theory}

Acoustic spectroscopy at frequencies up to $10 \mathrm{GHz}$ enables investigation of liquid substances with subclassic absorption caused by vibrational relaxation. The classical part is described by the Stokes-Kirchhoff equation, usually limited to the first part of the following equation due to negligible thermal conductivity $[1,2]$ :

$$
\left(\frac{\alpha}{f^{2}}\right)_{\text {class }}=\frac{2 \pi^{2}}{\rho_{0} c_{0}^{3}}\left[\frac{4}{3} \eta_{\mathrm{s}}+\kappa_{T}\left(\frac{1}{C_{v}}-\frac{1}{C_{p}}\right)\right],
$$

where $f$ is the frequency of an ultrasonic wave, $\rho$ is the density of the liquid, $c_{0}$ is the ultrasound speed for frequencies below the range of vibrational relaxation, $\kappa_{T}$ is the coefficient of thermal conductivity, $\eta_{\mathrm{s}}$ is the coefficient of shear viscosity, and $C_{p}$ and $C_{v}$ are the molar heat capacities at constant pressure and volume, respectively.

In the majority of cases, the relaxation in liquids, caused by translation-vibration transfer (Kneser effect), can be described using the following equation with a single relaxation time $\tau$ :

$$
\frac{\alpha}{f^{2}}=\frac{A}{1+\omega^{2} \tau^{2}}+B
$$

where $A$ and $B$ are absorptions in low- and high-frequency ranges, respectively, and $\omega$ is the angular frequency.

Acoustic irreversible processes in halogen derivatives of benzene were first observed in chlorobenzene [1]. Ultrasonic absorption in other halides as a function of frequency was presented in $[3,4]$. The physical nature of this process became clearer after systematic investigations of all these compounds in the gaseous phase [2].

Dependencies of kinetic and thermodynamic parameters on the temperature $T$ and the pressure $p$, as well as coincidence of the heat capacity $C_{i}$ calculated from acoustic measurements (Eq. 3) and the Planck-Einstein formula (Eq. 4), shown in Table 1, gives evidence that acoustic relaxation observed in all these compounds is caused by Kneser processes:

$$
\begin{aligned}
C_{(i \text { acoust })} & =\frac{A c}{2 \pi^{2}} \frac{C_{p} C_{v}}{\left(C_{p}-C_{v}\right) C_{i}}, \\
C_{i \text { opt }} & =R \sum_{i} g_{i} \frac{h v_{i}}{k T} \frac{\exp \left(-h v_{i} /(k T)\right.}{\left[1-\exp \left(-h v_{i} /(k T)\right]^{2}\right.},
\end{aligned}
$$


Table 1 Values of physical parameters obtained from acoustical and spectroscopic measurements as well as values calculated from the Planck-Einstein equation in benzene and its monosubstituted halide vapors $[2,5]$

\begin{tabular}{lllllll}
\hline No & Parameter & $\mathrm{C}_{6} \mathrm{H}_{6}$ & $C_{6} \mathrm{H}_{5} \mathrm{~F}$ & $\mathrm{C}_{6} \mathrm{H}_{5} \mathrm{Cl}$ & $\mathrm{C}_{6} \mathrm{H}_{5} \mathrm{Br}$ & $\mathrm{C}_{6} \mathrm{H}_{5} \mathrm{I}$ \\
\hline 1 & $T(\mathrm{~K})$ & 303.2 & 304.1 & 304.8 & 326.7 & 342.7 \\
2 & $f_{\mu} p^{-1}\left(10^{2} \mathrm{~s}^{-1} \cdot \mathrm{Pa}^{-1}\right)$ & 0.95 & 5.73 & 14.4 & 18.5 & 27.6 \\
3 & $f_{\mathrm{c}} p^{-1}\left(10^{2} \mathrm{~s}^{-1} \cdot \mathrm{Pa}^{-1}\right)$ & 1.05 & 6.32 & 15.8 & 20.4 & 30.6 \\
4 & $c_{0}\left(\mathrm{~m} \cdot \mathrm{s}^{-1}\right)$ & 188.5 & 169.6 & 157.4 & 137.8 & 123.5 \\
5 & $D$ & 1.101 & 1.104 & 1.101 & 1.102 & 1.105 \\
6 & $\varepsilon$ & 0.175 & 0.179 & 0.175 & 0.177 & 0.181 \\
7 & $\mu_{\text {max }, \text { opt }}$ & 0.302 & 0.311 & 0.303 & 0.307 & 0.315 \\
8 & $\mu_{\text {max }, \text { acoust }}$ & 0.289 & 0.314 & 0.337 & - & - \\
9 & $C_{i \text { acoust }}\left(\mathrm{J} \cdot \mathrm{mol}^{-1} \cdot \mathrm{K}^{-1}\right)$ & 51.4 & 62.5 & 64.8 & - & - \\
10 & $C_{i \text { opt }}\left(\mathrm{J} \cdot \mathrm{mol}^{-1} \cdot \mathrm{K}^{-1}\right)$ & 50.6 & 62.7 & 66.9 & 75.1 & 80.9 \\
11 & $\tau_{\mathrm{pS}}\left(10^{-9} \mathrm{~s}\right)$ & 18.7 & 3.13 & 1.25 & 0.97 & 0.65 \\
12 & $C_{p}^{0}\left(\mathrm{~J} \cdot \mathrm{mol}^{-1} \cdot \mathrm{K}^{-1}\right)$ & 83.8 & 95.7 & 98.9 & - & - \\
13 & $\kappa_{0}\left(C_{p} C_{v}^{-1}\right)$ & 1.110 & 1.095 & 1.092 & 1.098 & 1.092 \\
14 & $\rho_{\text {liquid }} \rho_{\text {gas }}^{-1}$ & 261.9 & 247.5 & 223.3 & 228.1 & 221.6 \\
15 & $\beta_{\mathrm{a}}$ & 8.49 & 8.52 & 8.24 & 8.28 & 8.27 \\
\hline
\end{tabular}

where $c$ is the speed of ultrasound; $R, h, k$ are the universal gas, Planck, and Boltzmann constants, respectively, $v_{i}$ is the vibrational frequency of a molecule, and $g_{i}$ is the degeneration degree of the $i$ th mode. Values shown in Table 1 are calculated from equations presented below. The ultrasonic absorption per wavelength $\mu_{\text {acoust }}$ and its maximum value $\mu_{\max }$ were obtained from the absorption or velocity measurements:

$$
\begin{aligned}
\mu_{\mathrm{acoust}} & =\alpha \lambda \approx \frac{\pi R C_{i}}{C_{v}\left(C_{p}-C_{i}\right)} \frac{\omega \tau^{\prime}}{1+\omega^{2} \tau^{\prime 2}}, \\
\mu_{\max } & \approx \frac{\pi}{2}\left(\frac{c_{\infty}}{c_{0}}-\frac{c_{0}}{c_{\infty}}\right)=\frac{\pi}{2} \frac{D^{2}-1}{D}=\frac{\pi}{2} D \varepsilon,
\end{aligned}
$$

where

$$
\frac{c_{0}^{2}}{c^{2}}=1-\frac{R^{\prime} C_{i}}{C_{v}\left(C_{p}-C_{i}\right)} \frac{\omega^{2} \tau^{\prime 2}}{1+\omega^{2} \tau^{\prime 2}} .
$$

The dispersion of ultrasonic waves is

$$
\frac{\alpha}{f^{2}}=\frac{A}{1+\omega^{2} \tau^{\prime 2}}+B,
$$


the relaxation force is

$$
\varepsilon=\frac{A f_{\mathrm{c}} c_{0}}{\pi}-\frac{1}{4}\left(1-\frac{2 B}{A}\right)\left(\frac{A f_{\mathrm{c}} c_{0}}{\tau}\right)^{2},
$$

and the adiabatic compressibility coefficient is

$$
\beta_{\mathrm{a}}=\sqrt{\frac{1}{\rho c^{2}}},
$$

where $c_{0}$ and $c_{\infty}$ are speeds below and above the relaxation region, $f_{\mathrm{c}}$ is the inflection point of the curve $\alpha f^{-2}(f), \tau$ is the relaxation time, and $\tau^{\prime}=\frac{c_{\infty}}{2 \pi f_{\mathrm{c} c_{0}}}$.

Acoustic investigations of compounds in the liquid phase $[4,6-8]$, carried out over wide temperature and frequency ranges, did not contradict any conclusions about the vibrational character of the relaxation drawn earlier. From acousto-optical investigations of halides in the hypersonic range [9-11], a linear dependence of the probability excitation $\operatorname{logarithm} \log \left(P_{10}\right)$ on $T^{-1 / 3}$ was found. It is one of the most characteristic features of relaxation, related to a delay of the internal energy distribution among vibrational and translational degrees of freedom of the molecules [12,13]. Correlation of the values of $C_{(i \text { acoust })}$ and $C_{(i \mathrm{opt})}$ indicated that in these relaxation processes all vibrational degrees of freedom were involved.

\section{Experimental Part}

The ultrasonic absorption spectra $\alpha f^{-2}(f)$ were measured by the ultrasonic pulse method in the frequency range from $10 \mathrm{MHz}$ to $10 \mathrm{GHz}$ [12] and in the frequency range below $5 \mathrm{MHz}$ by the resonator (Eggers) method. The ultrasonic velocities were obtained using an ultrasonic pulse-phase interferometer or sing-around transit time method [14]. The temperature was stabilized with $0.01 \mathrm{~K}$ uncertainty.

The measurement uncertainties ranged from $7 \%$ to $4 \%$ for the attenuation in the frequency range of $10 \mathrm{MHz}$ to $60 \mathrm{MHz}$, from $3.5 \%$ to $5.5 \%$ in the frequency range of $0.4 \mathrm{GHz}$ to $10 \mathrm{GHz}$, and from $2 \%$ to $9 \%$ for frequencies below $5 \mathrm{MHz}$.

Measurements reported in this article were performed using the following chemical substances: benzene-HPLC grad, Aldrich or $99+\%$ A.C.S. Aldrich, nitrobenzene-99+\% A.C.S. Aldrich, aminobenzene-99.5+\% A.C.S.-Aldrich, $\mathrm{C}_{6} \mathrm{H}_{5} \mathrm{~F}-$ $99 \%$ Aldrich, $\mathrm{C}_{6} \mathrm{H}_{5} \mathrm{Cl}-99+\%$ Aldrich, $\mathrm{C}_{6} \mathrm{H}_{5} \mathrm{Br}-99+\%$ Aldrich, and $\mathrm{C}_{6} \mathrm{H}_{5} \mathrm{I}-98 \%$ Aldrich. They were used without additional purification.

\section{Results and Discussion}

For bromo-, chloro-, fluoro-, iodo-, and nitrobenzene, as well as for toluene and aniline, investigations of non-reversible processes using a new possibility of absorption measurements by the impulse method [15] at hypersonic frequencies resulted in better accuracy of absorption values and better accuracy of parameters related 

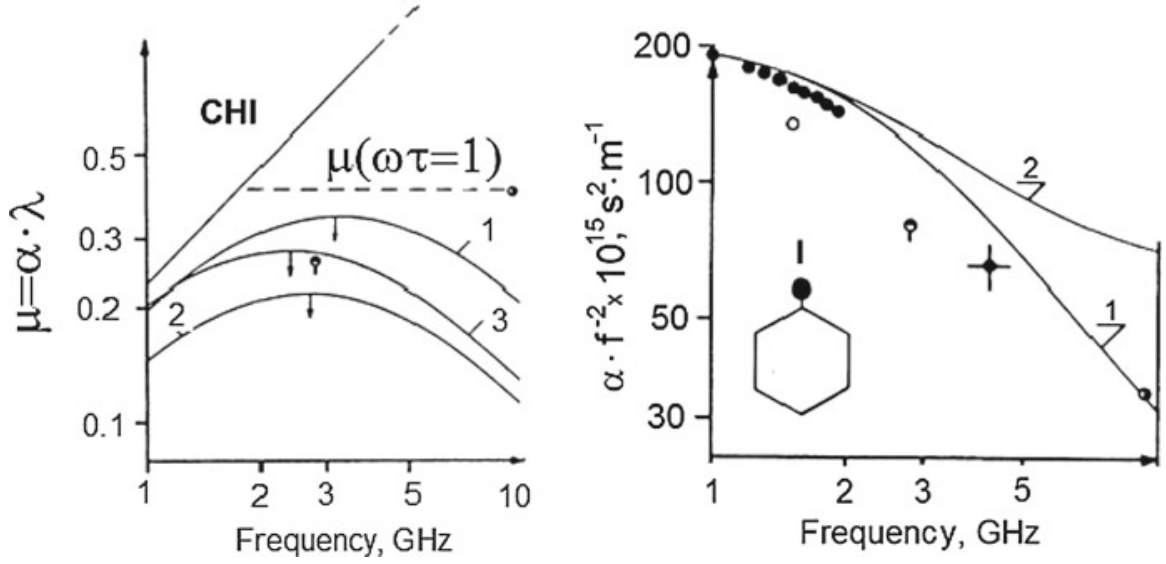

Fig. 1 Comparison of relaxation curves $\mu(f)$ and $\alpha f^{-2}(f)$ obtained by authors (1), and earlier by other authors (2)—[9]; (3)—[8] for iodobenzene at 293.2 K

to the relaxation process. It was shown that processes observed in all investigated compounds were closely related to translation-vibration transitions for all degrees of freedom. This is in contradiction with earlier explanations [7,8]. The probable reason of discrepancies between our and previous research, which conveyed a different conclusion, is an incorrect interpretation of Mandelstam-Brillouin spectra $[6,9,10]$. In these papers there was no explanation about the analysis of the spectra obtained in the region of relaxation of $2 \mathrm{GHz}$ to $6 \mathrm{GHz}$ and probably the data handling was done without taking into account the Rytov-Mountain line [16]. Its influence on the results obtained for $\mathrm{CCl}_{4}$ was shown in many papers [17-20].

Results of ultrasonic measurements of absorption $\mu$ and $\left(\alpha f^{-2}\right)$ as a function of frequency (in the $\mathrm{GHz}$ range) for halogenated benzenes in comparison with earlier measurements $[8,10]$ are presented in Fig. 1, Tables 1, 2, and 3.

Other acoustic properties: the dispersion $D$, the relaxation force $\varepsilon$, the relaxation time $\tau$, and the absorptions $\mu_{i \text { opt }}$ and $\mu_{i}$ ac, calculated from optical and acoustical experimental results, respectively, and classical absorption are presented in Table 1.

Dependencies obtained in our investigation show much better essential physical properties of halogens of benzene, because the correction introduced to calculations performed for these compounds in the highest experimental frequency range [15] does not need any extrapolation when estimation of the appropriate values is concerned.

Acoustical parameters: the maximum absorption $\mu_{\max }$, the relaxation force $\varepsilon$, the dispersion of ultrasonic velocity $D$, and the heat capacity $C_{\text {acoust }}$ for chloro- and bromobenzene presented in the Inoue paper [9] are in good agreement with our data. However, due to small discrepancies in characteristic frequencies $\left(f_{\alpha} f^{2}, f_{\mu}\right.$, and $\left.f_{\mathrm{c}}\right)$, caused by not entirely correct extrapolation of $\alpha f^{-2}(f)$ and $\mu(f)$ curves, results given in [9] are non-realistic in the case of high-frequency absorption asymptotes, $-B+\left(\alpha f^{-2}\right)_{\text {class. }}$. These results are completely different from asymptotes obtained 


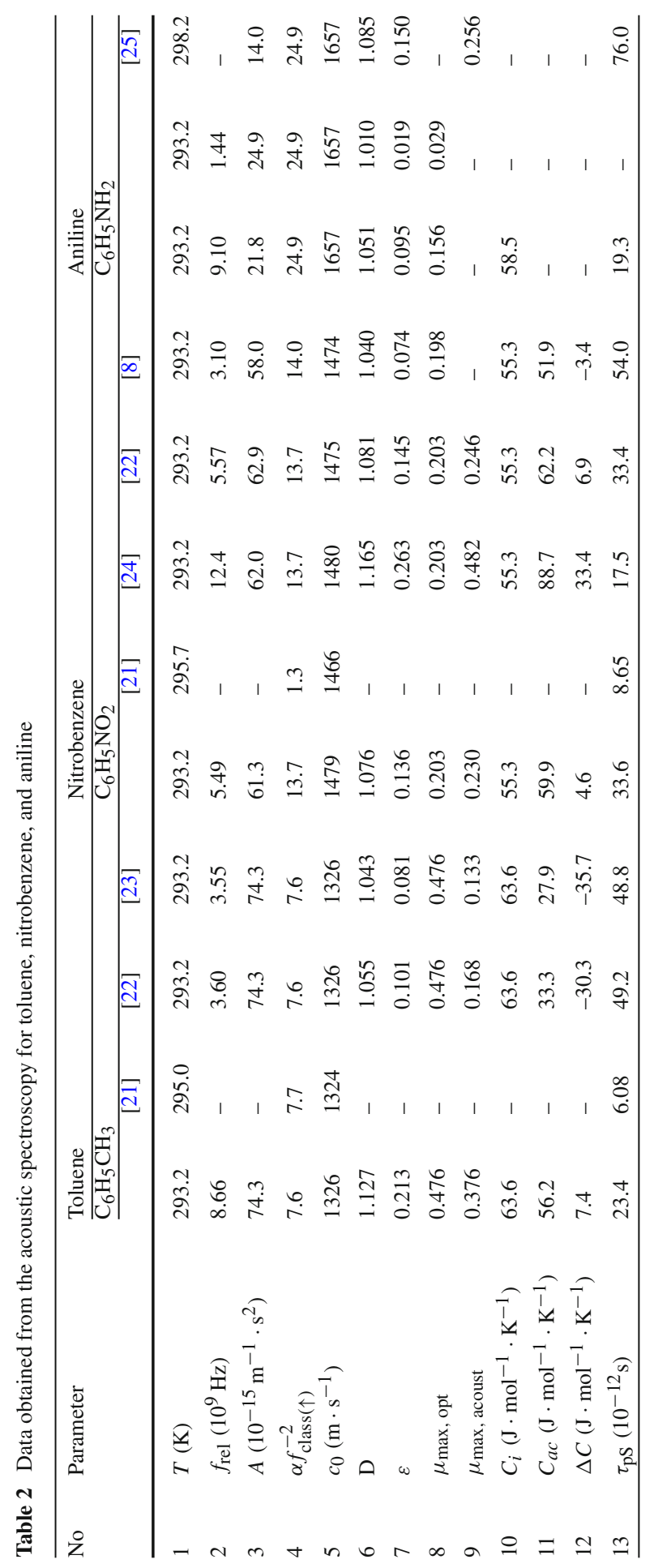




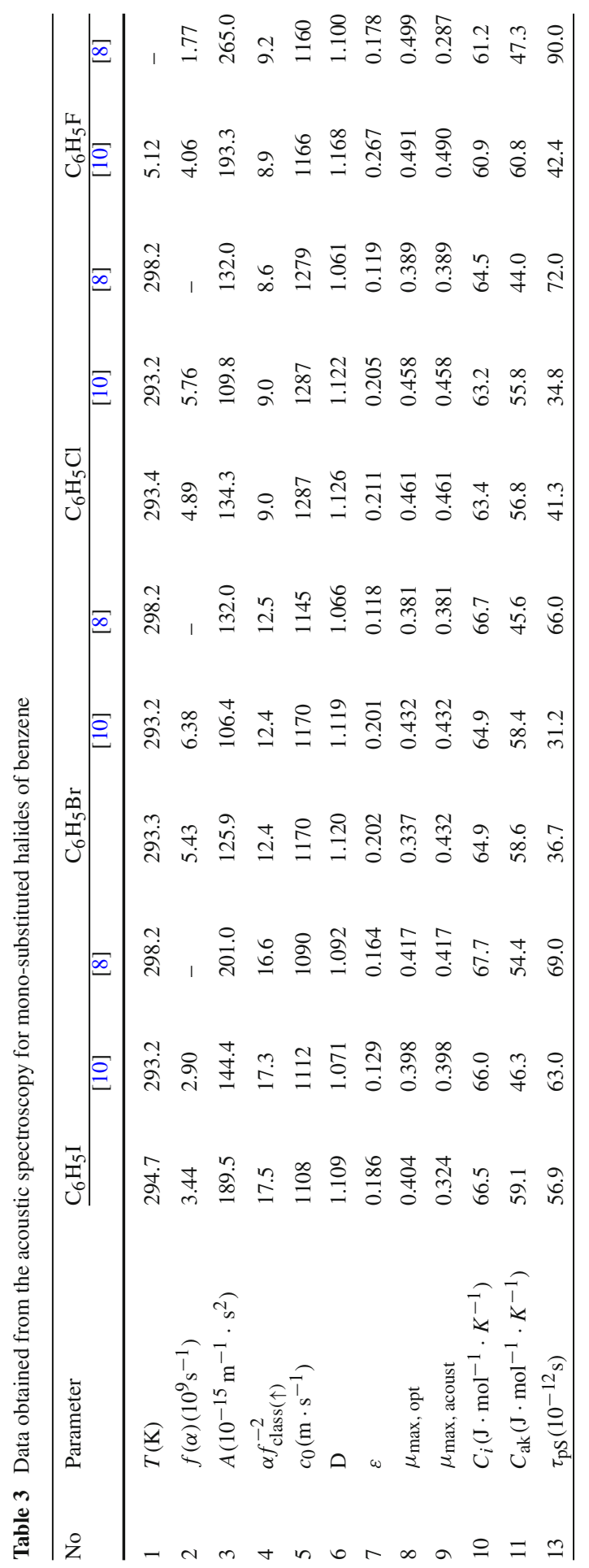




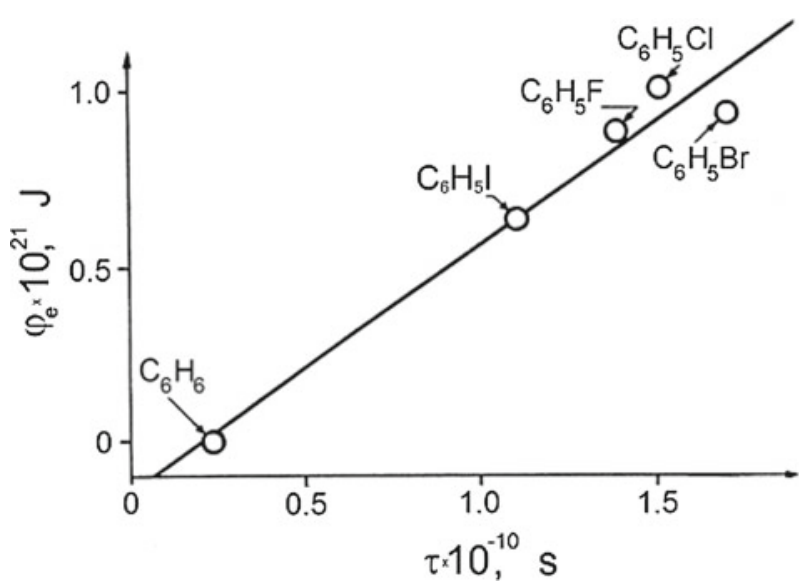

Fig. 2 Intermolecular potential of the dipole-dipole interaction for benzene and its derivatives as a function of the relaxation time

by us at $10 \mathrm{GHz}$ [26]. The main reason for discrepancies between our data and the absorption coefficients $\mu_{\max }$, and relaxation times $\tau_{\mathrm{PT}}$ and $\tau_{\mathrm{PS}}$ reported by Parpiev et al. [7] is probably connected with extrapolation-based estimation of these parameters carried out in the mentioned paper. The highest experimental frequency in it was $2 \mathrm{MHz}$, and was lower than $f_{\mathrm{c}}$.

The reason for the discrepancy in the description of irreversible processes in iodobenzene is analogical, but has a smaller impact. It is probably caused by a better correlation of experimental results for hypersonic absorption. To analyze irreversible processes in mono-substituted halogens of benzene, selected literature data about the structure of molecules $\mathrm{C}_{6} \mathrm{H}_{5} \mathrm{X}(\mathrm{X}=\mathrm{F}, \mathrm{Cl}, \mathrm{Br}, \mathrm{I})$ with $\mathrm{C}_{2 v}$ symmetry were used. Such a model with a planar, regular hexagon possesses 30 normal vibration modes, which were taken into account during calculation of the heat capacity $C_{\mathrm{ac}}$ from the PlanckEinstein equation (Eq.4). Available data about the frequency part of the vibrational spectrum are changing due to constant improvement of the accuracy of measuring techniques and widening of the frequency range. Data shown in [27] significantly differ from those shown in [28], although the latter are still used for handling data obtained from acoustic spectroscopy [10]. For these molecules a significant influence of dipole moments $D_{\mathrm{e}}$ on thermodynamic properties and kinetics of phenomena is observed-a change of these physical values correlates with changes in the vibrational relaxation time, and also with the probability of VT processes (transition from translational to vibrational degrees of freedom). This relation is shown in Fig. 2.

For these compounds an additional term responsible for long-range dipole interactions appears in the intermolecular potential (in the Stockmayer relation [29]) - the dipole interaction $\varphi_{\mathrm{e}}$ :

$$
\varphi_{\mathrm{e}}=g \frac{D_{\mathrm{e}}^{2}}{\rho^{3}} .
$$




\subsection{Other Derivatives of Benzene}

The transformation of a flat structure of halogen-substituted benzene into a threedimensional structure by substitution of halide atoms with $\mathrm{NO}_{2}, \mathrm{NH}_{2}$ and $\mathrm{CO}_{3}, \mathrm{NO}_{2}$ groups accelerates slightly the kinetics of unequilibrated (irreversible) processes. Such processes may be regarded as vibrational relaxation, i.e., the energy transfer between translational and vibrational degrees of freedom.

Although there are no isomeric forms of molecules with distinguishable energy states, one can imagine a frozen rotation of amino- and nitro-groups around the phenyl ring. For symmetry assumed in toluene, one of the hydrogen atoms of the methyl group lies within the plane of the phenyl group, while the two remaining ones are located symmetrically at both sides of the ring plane. The interaction between phenyl and methyl groups results in an energy barrier which prevents rotation [30]. However, no different isomers are observed.

Having in mind the above and according to molecular acoustics [14], no rotational isomeric relaxation should be observed in these compounds. This, together with the temperature dependence of relaxation and dispersion times in nitrobenzene $[8,24]$ and toluene [23], indicates that the unequilibrated processes observed are related to vibrational relaxation.

Since all chemical compounds dealt with herein belong to this group, it seems worthwhile to consider some alternative interpretations and analyze the data more accurately (Table 2), taking also into account new measurements carried out at $10 \mathrm{GHz}$.

Figure 3 shows the comparison of experimental results obtained for the propagation and absorption of ultrasonic waves for the above compounds, reported by several authors [8,21-25], which indicates the presence of relaxation processes. Dispersion observed in toluene and nitrobenzene and its temperature dependence suggest that the relaxation detected is a Kneser-type process. On the other hand, the temperature dependence of absorption for aniline is a manifestation of a relaxation process related to the breaking and formation of associated molecules.

\subsection{Toluene}

Acoustic spectroscopic data for toluene in a broad frequency range [35-37] presented in Fig. 4 shown that the activation energy is about $8.4 \mathrm{~kJ} \cdot \mathrm{mol}^{-1}$ and the relaxation frequency is about $0.25 \mathrm{MHz}$. This seems to be associated with oscillations of the methyl group [36]. The parameters of low-frequency relaxation reported in many cited papers are contradictory. All authors noted that no other processes could be observed above the low-frequency relaxation range up to about $1 \mathrm{GHz}$.

As reported elsewhere [32,43], such a process was observed for the first time in investigations of the frequency dependence of the velocity and the absorption. Later it was confirmed in numerous papers (Fig. 5) and examined more accurately over a broadened frequency range. Relevant data are summarized in Table 2 and in Fig. 5. It is important that our values of quantities describing the relaxation process, obtained at high Gigahertz frequencies, are in good correlation with optical dispersion measurements carried out by Mandelshtam-Brillouin scattering at $4.5 \mathrm{GHz}$ and $6.5 \mathrm{GHz}$. 
Fig. 3 Temperature dependence of ultrasonic velocity in benzene derivatives: 1, 4- [30];

2, 9-authors results; 3 - [21]; 5-[31]; 6-[32,33]; 7-[25]; $8-[34]$

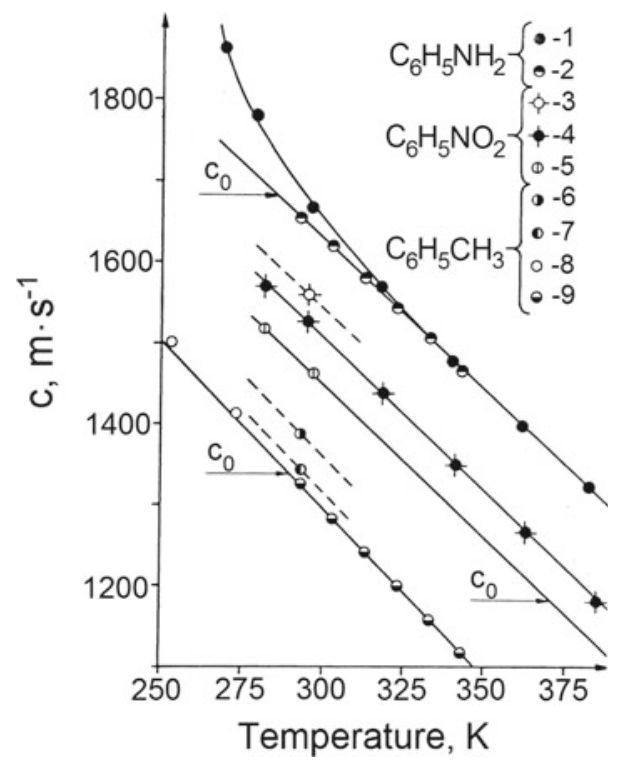

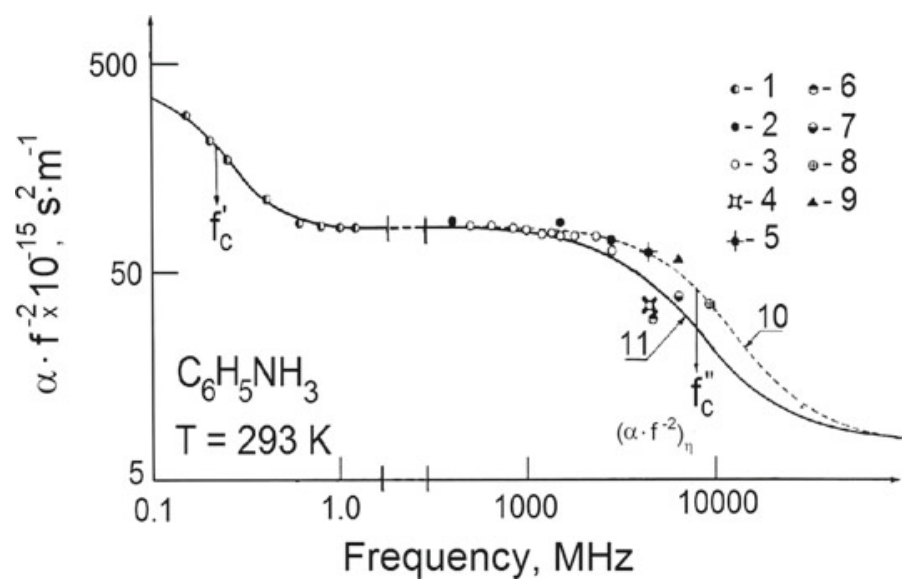

Fig. 4 Dependence of ultrasound absorption frequency: 1-[38];2-[3,4];3-[39-42]; 4-[22,43]; 5-[44]; 6-[45]; 7-[21]; 8-[15]; 9-[36]; 10-approximation following from results of acoustic experiments; 11 -influence on it by data presented in other studies $[21,22,43,45]$

Results of precise measurements of hypersonic wave velocities $[33,53,54]$ are in close agreement with the dispersion relationship obtained in absorption experiments (Fig. 5).

The observed phenomenon is related to vibrational relaxation, which is confirmed not only by acoustic but also by thermodynamic quantities. The molar heat capacity determined in ultrasonic experiments is comparable to that obtained from the PlanckEinstein formula (Eq.4). 


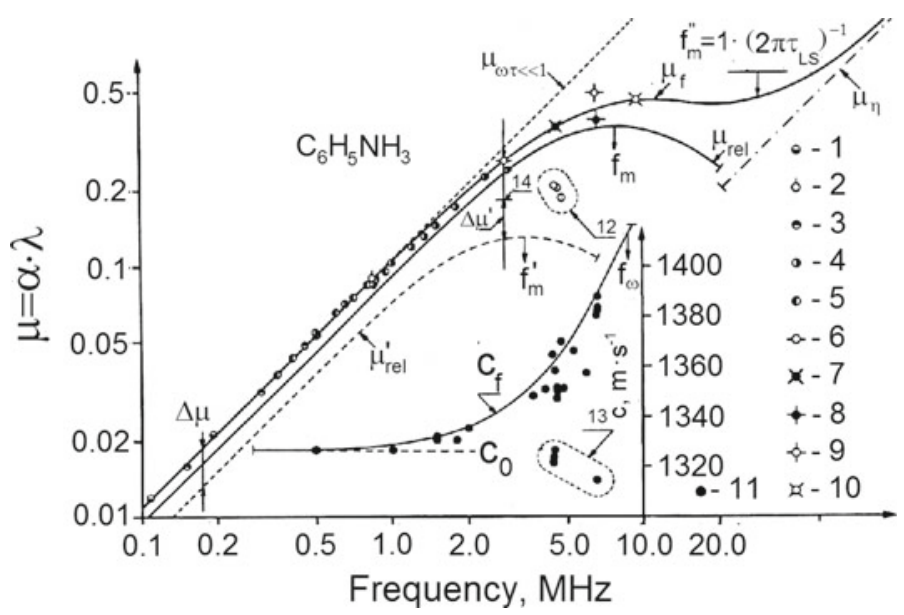

Fig. 5 Analysis of relaxation in toluene: $1-[46] ; 2-[47] ; 3-[48] ; 4-[39-42] ; 5-[49] ; 6-[4] ; 7-[44]$; 8-[21]; 9-[36]; 10—[15]; 11—dispersion data; 12—[21,43,45,50]; 13—[1,43,51,52]

It should also be pointed out that the examination of spectrograms of depolarization Rayleigh scattering as a function of pressure and temperature in toluene show a relaxation related with rotational isomerism [55] with a relaxation time $\tau_{\mathrm{ls}} \sim 5.6 \times 10^{-12} \mathrm{~s}$, as illustrated in Fig. 5 over a frequency range of about $30 \mathrm{GHz}$. As was stated in our other papers [56], this time is linearly dependent on the viscosity, i.e., in the case of toluene, an increased pressure or a lowered temperature shifts the relaxation time towards an experimentally more easily available region (lower frequencies).

In addition, under such conditions of $(p, T)$, the fine structure of Rayleigh lines develops in toluene. This is in accordance with the presence of sound velocity dispersion in the low-temperature range [23]. Nonetheless, many authors confined the discussion of results by an assumption about the existence of two unequilibrated vibrational processes in which two vibrations participate-in-plane and out-of-plane vibrations with low modes $\theta_{i p} \sim 492 \mathrm{~K}$ and $\theta_{\text {op }} \sim 295 \mathrm{~K}$. Such an interpretation is in contradiction to the latest data.

Figure 5 shows the relationship for $\mu_{\text {rel }}^{\prime}$ from a paper on low-frequency relaxation [23]. If one assumes that a faster unequilibrated process corresponds to frequencies $f \ll f_{\mathrm{m}}^{\prime}$, then even at $2.8 \mathrm{GHz}$, the quantity $\mu_{\mathrm{f}}^{\prime}=\mu_{\text {rel }}^{\prime}+\mu^{\prime}$ should not exceed the level shown in the plot [13]. However, the difference $\mu_{\mathrm{f}}-\mu_{\mathrm{f}}^{\prime}$ calculated using values given in [23] at this frequency is about $30 \%$, and is about $35 \%$ when using our results [15] at $\sim 10 \mathrm{GHz}$. Therefore, we cannot agree with the interpretation of relaxational data presented in [23], which based on the observed dispersion of the ultrasonic wave frequency, is where apparently the specific character of data behavior in the region $\omega \tau \sim 1$ has not been taken into account.

\subsection{Nitrobenzene}

Ultrasonic examination of solutions of nitrobenzene [57] and unassociated liquids in benzene, chloroform, chlorobenzene, and toluene have shown that an increased 
concentration of $\mathrm{C}_{6} \mathrm{H}_{5} \mathrm{NO}_{2}$ molecules causes a systematic nonlinear decrease in the absorption of ultrasound in such binary mixtures. This means that nitrobenzene molecules accelerate the energy transfer to vibrational degrees of freedom. At the same time, the concentration dependence of the absorption of ultrasound in the region $\omega \tau \sim 1$ allows one to state that characteristic relaxation times of pure fractions of these compounds are of the same order of magnitude, and are markedly shorter than the ones of benzene and chloroform. Indeed, in the first hypersonic experiments [21] the occurrence of unequilibrated properties was observed at about $7.62 \mathrm{GHz}$. Although the measured velocities $v_{\mathrm{f}}$ of hypersonic waves are close to those obtained later in more precise experiments [24,50], the assessment of the characteristic frequency $f_{\tau}=18.4 \mathrm{GHz}$ and the relaxation time in [21] is not correct. The nature of the phenomenon became clear after systematic investigations $[8,58]$, in which Kneser's processes were proposed to explain the relaxation for the first time. The only difference of further approaches lies only in recorded kinetic and thermodynamic characteristics of the process, and more precise values of the parameters received from acoustic experiments at hypersonic frequencies $[4,15]$.

Table 2 summarizes acoustic spectroscopy data for nitrobenzene reported in several papers cited therein. The discrepancies between the quantities describing the relaxation process are probably caused by wrong estimates of relaxation times, resulting from a too narrow frequency range used in acoustic experiments and too big errors in acoustooptical investigations. Instrumental errors were discussed in [59]. When experimental data $v_{0}$ or $A$ are available only in a narrow relaxation range, the assessment of $v_{\infty}$ and relaxation time $\tau$ may be burdened with a very large error.

Figure 6 shows the relation $\mu_{\mathrm{f}}$ obtained for all known available data. The high accuracy of dispersion measurements [50] confirms the discussion of the authors because the results of acoustic data analysis and acousto-optical experiments [50] are consistent (Table 3). In addition, the dispersion dependence of $v_{\mathrm{f}}$ (Fig. 6) determined in acoustic experiments is in line with results given in $[24,50]$ within the limit of the cited error.

\subsection{Aniline}

The concentration dependence of ultrasonic wave absorption in a binary mixture of aniline and nitrobenzene [60] allows one to assume that the acoustic relaxation times of these compounds are of the same order of magnitude. This holds true only when the nature of absorption, higher than that resulting from classic processes, i.e., the delay in reaching equilibrium after disturbance with the ultrasonic wave, may be associated with energy transfer between translational and vibrational degrees of freedom of the molecules. It might seem that such an assumption is contradicted by the negative temperature absorption coefficient of the ultrasonic wave in this solution and the type of temperature dependence of the dispersion parameter $D$, characteristic of associated compounds (Fig. 3). However, at room temperature (293 K) the viscosity of aniline is the highest among the above described compounds and grows nonlinearly with decreasing temperature. This is related with the presence of hydrogen bonds $\mathrm{NH} \cdot \cdots \mathrm{N}$, which cannot be broken by thermal molecular motion. Thus, the temperature 


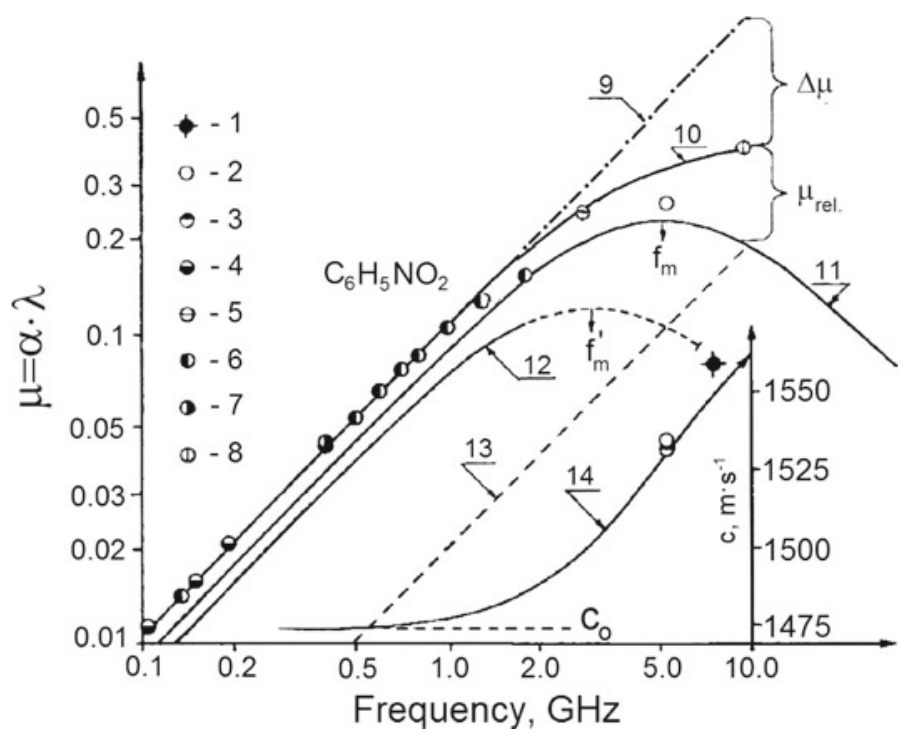

Fig. 6 Acoustical spectroscopy of nitrobenzene: 1-[21]; 2-[50]; 3-[30]; 4-[46]; 5-[4]; 6-[8,6]; 7-[3]; 8-[15]; 9-asymptote $\mu_{\omega \tau \ll 1} ; 10$-dependence of $\mu_{\mathrm{f}} ; 11$-dependence of $\mu_{\mathrm{rel}}=\mu_{\mathrm{f}}-\mu_{\eta}$; 12 -dependence of $\mu$ for the data from [8]; 13-value of $\mu_{\eta} ; 14$-dispersion of hypersound velocity

dependence of sound absorption, untypical for vibrational relaxation, may be explained by a considerable share of the shear viscosity at high frequencies, since the shear relaxation time is usually proportional to the viscosity.

The above introductory remarks allow analyzing in detail the unequilibrated properties of aminobenzene (aniline), the nature of which has not been discussed previously. Ideas of possible structural relaxation were presented in [61], with simultaneous manifestation of structural and vibrational relaxation [22] and phenomena related with rotational isomerism and structural changes [46]. However, no facts or proofs regarding the choice of the relaxation model were discussed.

Relaxation phenomena in aniline were for the first time observed in investigations on Mandelstam-Brillouin scattering [62] which, similar to ultrasonic experiments [63], demonstrated the presence of acoustic wave velocity dispersion. In later experiments with hypersonic waves $[15,42,54,64,65]$, the authors managed to investigate in detail the relaxation process by studying changes in the velocity and the absorption of waves in a broad frequency range. Next, systematic temperature experiments carried out in aniline $[22,24,25]$ revealed the shift of the relaxation region towards lower frequencies, i.e., an elongation of the relaxation time and an increase in the relaxation strength (Eq.9) and the wave absorption coefficient. Figure 7 shows all experimental results for $293.2 \mathrm{~K}$ and several theoretical curves.

The dashed area in Fig. 7 represents the region where the coefficient $\mu_{\mathrm{ms}}$ and the characteristic frequency (shear viscosity relaxation) change up to the melting point of aniline. It is obvious that the behavior of the ultrasonic wave velocity $v_{\mathrm{f}}$ at the highest frequencies depends mainly on the share of vibrational relaxation. 


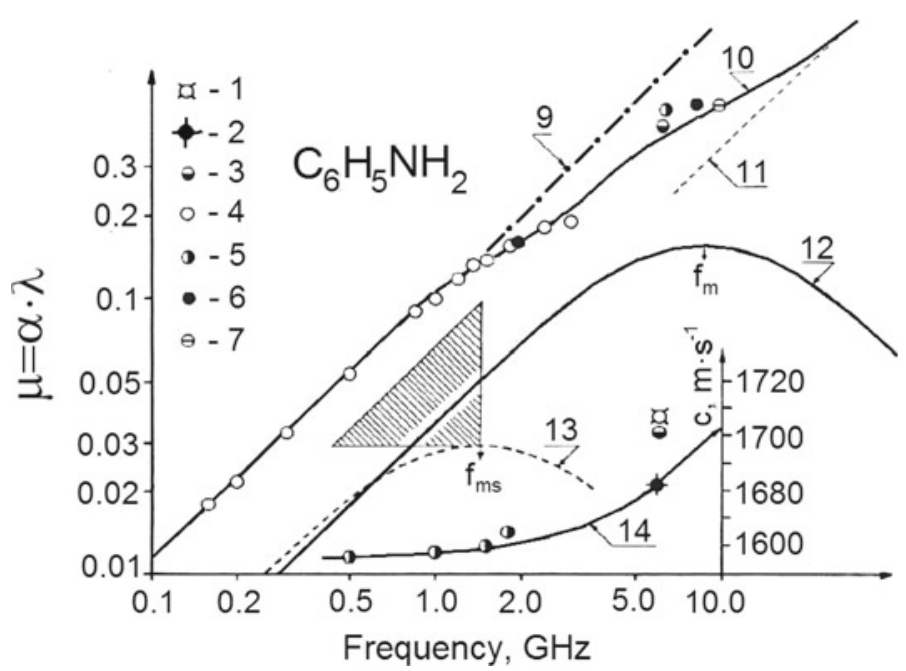

Fig. 7 Analysis of acoustic spectroscopy data in aniline: 1-[22]; 2-[30]; 3-[44]; 4-[42]; 5-[54]; 6-[22,23]; 7-[15]; 9-asymptote $\mu_{\omega \tau \ll 1}(T=293 \mathrm{~K}) ; 10-\mu_{\mathrm{f}} ; 11-\mu_{\mathrm{B}} ; 12-\mu_{\text {rel }} ; 13-\mu_{\eta} ; 14-v_{\mathrm{f}}$

\section{Conclusions}

An analysis of possible reasons for discrepancies between results and experimental facts obtained for investigated substances was performed. This analysis showed that acoustic relaxation observed in a liquid phase is a Kneser-type process with all vibrational degrees of freedom involved. It can be described by a single relaxation time, as was the case for many other substances [12,66-68].

Some relations between the relaxation time, the absorption, and the structure of compounds have been observed especially for the gas phase. For gases, the bigger the molecule of the substituent, the shorter is the relaxation time. For liquids, the bigger the molecule of the substituent, the shorter is the relaxation time (with the exception of I), the lower is the low-frequency absorption and $\mu_{\max }$ (except for iodine), the smaller is the relaxation force, the smaller is dispersion, and an increasing significance of classic absorption is clearly visible.

There is also an interesting correlation between the acoustical properties and the dipole moments for saturated and non-saturated compounds $[13,66]$. However, a complete explanation of these dependencies needs further physical investigations of similar cyclic and heterocyclic compounds.

It can be concluded that the observed irreversible processes in benzene derivatives with amino-, nitro-, and methyl- groups and halides display typical ultrasonic vibrational relaxation, slightly hindered by peculiarities with frozen rotations of larger groups and more dynamic processes of formation and breaking of hydrogen bonds.

Acknowledgments The work was supported by the University of Gdańsk (DS 5200-4-024-2011) and prepared within the framework of the co-operation agreement between the Institute of Physics and Technology, Academy of Sciences of Turkmenistan, Ashgabat, Turkmenistan, and the University of Gdańsk, Poland. 
Open Access This article is distributed under the terms of the Creative Commons Attribution License which permits any use, distribution, and reproduction in any medium, provided the original author(s) and the source are credited.

\section{References}

1. S.E.A Hakim, W.J. Comley, Nature 208, 5015 (1965)

2. W.A. Bashlachev, Issledovanie kolebatelnoy relaksaci v parakh riada galogenzamesh-chenykh benzola, Ph.D. Thesis (Moscow, 1967)

3. K.G. Plass, Acustica 19, 236 (1967/68)

4. K.G. Plass, Ber. Bunsen Ges. Phys. Chem. 74, 343 (1970)

5. W.A. Bashlachev, Yu.A. Bashlachev, Yu.A. Bytylev, I.P. Lavrentev, W.F. Yakovlev, Trudy 6 Vcesoyuznoy Akusticheskoy Konferenci, Moscow, 1968

6. S.S. Aliev, L.E. Kvasova, L.V. Lanshina, K. Parpiev, P.K. Khabibulayev, Akust. Zh. 16, 304 (1970)

7. K. Parpiev, P.K. Khabibulaev, M.G. Khaliulin, Akust. Zh. 15, 466 (1969)

8. P.K. Khabibulaev, M.G. Khaliulin, S.S. Aliev, K. Parpiev, M.I. Shakhparonov, O kolebatelnoy akusticheskoy relaksaci $w$ zhidkostiakh, Fizika i fiziko-chimia zhidkostey (Izdatelstvo MGU, Moscow, 1972)

9. N. Inoue, J. Phys. D 13, 1699 (1980)

10. W. Mersch, G. Fytas, Th. Dorfmüller, Ber. Bunsen Ges. Phys. Chem. 81, 419 (1977)

11. D. Sette, Rilassamento elastico e structura dei liquidi. Ric. Sci. 22, 706 (1952)

12. N.B. Lezhnev, Issledovanie Kolebatelnoy Relaksaci w Zhidkostyakh Metodami akusticheskoy Spektroskopi na Sverkhvysokikh chastotakh, Doktorskaya Dissertacya (Akademia Nauk Turkmenistanu, Ashgabad, 1982)

13. B.B.J. Linde, N.B. Lezhnev, Ultrasonics 38, 945 (2000)

14. A.K. Matheson, Molecular Acoustics (Wiley-Interscience, London, 1971)

15. N.B. Lezhnev, Akust. Zh. 21, 2 (1981)

16. R.D. Mountain, Bull. Am. Phys. Soc. Ser. 2, 86 (1966)

17. G.I.A. Stegman, B.P. Stoicheff, W.S. Gornall, J. Volterra, J. Acoust. Soc. Am. 49, 979 (1971)

18. S.M. Rytow, Zh. Eksp. Teoret. Fiz. 33, 514 (1957)

19. D. Steele, E.R. Lippincott, J. Xavier, J. Chem. Phys. 33, 1242 (1960)

20. R.D. Mountain, Rev. Mod. Phys. 38, 205 (1966)

21. P.A. Fleury, R.J. Chiao, J. Acous. Soc. Am. 39, 751 (1966)

22. V.A. Parzyan, Kinetika bystrykh processov pierestroiki struktury i mekhanizma assocya-cii zhidkogo anilina i niekotorykh ikh proizvodnykh, Ph.D. Thesis (Moscow, 1970)

23. V.A. Parzyan, E.O. Rabichev, Vestn. Mosk. Univ. Ser. Khimia 3, 370 (1975)

24. K. Oda, R. Hayakawa, Y. Wada, Jpn. J. Appl. Phys. 12, 1326 (1973)

25. D.H. Rank, E.M. Kiess, U. Fink, T.A. Wiggins, J. Opt. Soc. Am. 55, 925 (1965)

26. N. Inoue, M. Ishiguro, Jpn. J. Appl. Phys. 18, 671 (1979)

27. L.M. Sverdlov, M.A. Kovner, E.P. Kraynov, Kolebatelnyie Spektry Mnogoatomnykh Molekul (Nauka, Moscow, 1970)

28. G. Herzberg, Kolebatelnyie i Vrashchatelnyie Spektry Mnogoatomnykh Molekul (Izd. Innostr. Lit., Moscow, 1949)

29. F. Reif, Fizyka Statystyczna (PWN, Warszawa, 1973)

30. D.P. Eastman, A. Hollinger, J.R. Kenemuth, D.H. Rank, J. Chem. Phys. 50, 1567 (1969)

31. J.R. Pelam, J.K. Galt, J. Chem. Phys. 14, 608 (1946)

32. R.J. Chiao, B.P. Stoicheff, J. Opt. Soc. Am. 54, 1286 (1964)

33. G.B. Bendek, T. Greytak, Proc. IEEE 53, 1623 (1965)

34. S.K. Kor, S. Esme, Acustica 34, 182 (1976)

35. R.T. Beyer, J. Acous. Soc. Am. 23, 62 (1951)

36. R.J. Chiao, P.A. Fleury, in Proceedings of Physics of Quantum Electronics (McGraw-Hill, Inc., New York, 1966), p. 241

37. G.S. Verma, E. Yeager, in Proceedings of 3rd International Congress on Acoustics, Stuttgart, Germany, 1959, p. 559

38. T. Ohsawa, Y. Wada, in Proceedings of 6th International Congress on Acoustics J-4-9, Tokyo, Japan, 1968, p. 29 
39. A.A. Berdyiev, N.B. Lezhnev, V.V. Lapkin, M.G. Shubina, in Proceedings of 6th International Congress on Acoustics, J-5-3, Tokyo, Japan, 1968, p. 41

40. A.A. Berdyiev, N.B. Lezhnev, in Proceedings 7th International Congress on Acoustics, 19-M2, Budapest, Hungary, 1971, p. 5

41. A.A. Berdyiev, W.W. Lapkin, N.B. Lezhnev, Izv. Akad. Nauk Turkmen. SSR 2, 111 (1968)

42. A.A. Berdyiev, W.W. Lapkin, N.B. Lezhnev, Izv. Akad. Nauk Turkmen. SSR 3, 108 (1969)

43. D.I. Mash, V.S. Starunov, E.B. Tiganov, I.L. Fabielinskiy, Zh. Eksp. Teoret. Fiz. 49, 1764 (1965)

44. I.M. Arefiev, Issledovanie relaksacyonnykh yavleniy v zhidkostiakh i zhidkikh kristalakh, Ph.D. Dissertation, Ashgabad, 1977

45. L.W. Lanishina, Y.G. Shoroshev, M.I. Shakhparoniv, Dokl. Akad. Nauk SSSR 173, 70 (1967)

46. E.L. Heasell, J. Lamb, Proc. Phys. Soc. B-69, 869 (1956)

47. A.A. Berdyiev, N.B. Lezhnev, Akust. Zh. 12, 247 (1966)

48. A.S. Lagunov, B.A. Belinskiy, Ultrazvukovaya Tekh. 2, 60 (1966)

49. P.K. Khabibulayev, M.G. Khaliulin, Ultrazvukovaya Tekh. 3, 47 (1967)

50. V.S. Starunov, I.A. Fabielinskiy, Sovremennyie Problemy Fizicheskoy Khimii (Izd. MGU, Moscow, 1970), p. 5

51. G.B. Bendek, J.B. Lastovka, K. Fritsch, T.J. Greytak, Opt. Soc. Am. 54, 1284 (1964)

52. I.L. Fabielinskiy, O.A. Shustin, Dokl. Akad. Nauk SSSR 92, 285 (1953)

53. K. Takagi, K. Negishi, Jpn. J. Appl. Phys. 14, 29 (1975)

54. A.A. Berdyiev, W.W. Lapkin, N.B. Lezhnev, Izv. Akad. Nauk Turkmen. SSR 4, 28 (1971)

55. S. Claesson, D.R. Jones, Chem. Scripta 9, 103 (1976)

56. D. Sette, Acustica 5, 195 (1955)

57. J. Fujii, R.B. Lindsay, K. Urushihara, in Proceedings 4th International Congress on Acoustics, K-24, Copenhagen, 1962, p. 1

58. K. Parpiev, P.K. Khabibulaev, Yu.G. Shoroshev, Akust. Zh. 16, 617 (1970)

59. B.B.J. Linde, N.B. Lezhnev, Ultrasonics 44, 1467 (2006)

60. E. Garmire, C.H. Townes, Appl. Phys. Lett. 5, 84 (1964)

61. V.V. Lapkin, Metodika izmierenia i akusticheskiye izmierenia zhidkostiey na vysokikh i svierkhvysokikh chastotakh, Ph.D Thesis, Moscow, 1971

62. W. Schaaffs, Z. Phys. Chem. 194, 28 (1944)

63. W.J. Railstone, J. Acoust. Soc. Am. 11, 108 (1939)

64. B.B.J. Linde, N.B. Lezhnev, J. Mol. Struct. 754, 111 (2005)

65. B.B.J. Linde, N.B. Lezhnev, J. Phys. IV 137, 213 (2006)

66. B.B.J. Linde, Acoustical Spectroscopy of Cyclic and Heterocyclic Compounds, Ketones and Polluted Water Surface, Wydawnictwo Uniwersytetu Gdańskiego, ISBN 83-7017-738-7 (1997)

67. B.B.J. Linde, N.B. Lezhnev, Ultrasonics 36, 958 (1998)

68. B.B.J. Linde, N.B. Lezhnev, Mol. Quantum Acoust. 19, 143 (1999) 